\title{
THE EFFECTIVENESS OF STATE AND LOCAL REGULATION OF HANDGUNS: A STATISTICAL ANALYSIS
}

\author{
Martin S. GeISEl, ${ }^{*}$ Richard Roll, ${ }^{* *}$ \\ and R. StANTON WETTICK, JR.***
}

One aspect of the continuing debate over weapons control, apart from Constitutional issues, is whether legislation is inherently capable of reducing crime and deaths by shooting. The opponents of increased control, tacitly admitting that empirical evidence is one means for measuring the effect of weapons regulation, have contended that "[e]xpert opinion and compelling evidence seem to indicate that the amount or kind of crime in a community is not substantially affected by the relative ease with which a person can obtain a firearm." National - Rifle Association of America, The Gun Law PROBLEM 10. In the following study the authors employ data analysis techniques to examine the efficacy of state and municipal controls on handguns. They conclude that many lives would be saved if all states increased their level of control to that of New Jersey, the state having the most stringent gun control laws.

The current controversy over gun control centers on the effectiveness of stringent gun control legislation.' Proponents of increased statutory control contend that rigorous laws will reduce death and crime rates by curtailing firearm possession by minors and such irresponsible adults as felons, mental incompetents, addicts and alcoholics. They argue that this justifies minor inconveniences imposed on responsible citizens who use firearms for hunting, targetshooting and protection.

\footnotetext{
* Research Associate of Economics, Carnegie-Mellon University, B.S. 1963, Case Institute of Technology; M.B.A. 1965, University of Chicago.

** Assistant Professor of Economics, Carnegie-Mellon University. B.A.E. 1961, Auburn University; M.B.A. 1963, University of Washington; Ph.D. 1968, University of Chicago.

*** Assistant Professor of Law, University of Pittsburgh Law School. B.A. 1960, Amherst College; L.L.B. 1963, Yale Law School.

The authors are indebted to James H. Scott, Jr., for data collection and useful suggestions.

'For a general background to the gun control controversy see Congress and " Gun
} 
Opponents of increased control, however, argue that gun control legislation is not of sufficient value in the prevention of crime to justify the restrictions it places on the responsible citizen.2 They contend that death and crime rates are not perceptibly reduced through gun control because such legislation does not prevent the professional criminal-the alleged "root" of the problem-from obtaining firearms. Furthermore, even if these laws did reduce the number of firearms possessed by professional criminals, other equally lethal weapons are readily available as adequate substitutes. ${ }^{3}$

One possible reason for this polarity of opinion is the lack of reliable empirical information describing the relationship between gun control legislation and death and crime rates. This article will attempt to alleviate this deficiency by presenting an empirical study which correlates gun control with various death and crime rates for states and cities, while simultaneously accounting for the influence of other factors such as per capita income, education and population density.

\section{DESCRIPTION OF THE STUDY}

The study measures the effectiveness of gun control legislation by the extent to which differences in death and crime rates among the states and cities can be explained by the differences in gun control legislation while accounting for the effects of several other factors that may influence death and crime rates. Differences in death and crime rates among the states and cities were obtained by collecting data on the rates of homicide by firearm, total homicide, suicide by firearm, total suicide, aggravated assault by firearm, total aggravated assault, accidental death by firearm and robbery (hereinafter referred to as "death and crime rates") for the fifty states, the District of Columbia and the 129 United States cities whose popula-

Control" Proposals, 45 CosG. Dig. 289 (1966); Congress and the Vational Crinte Problem, 46 CoNG. DiG. 193 (1967); Harris, Amals of Legislation-If Youl Lose Your Gums, Tit: NEW YORKER, Apt. 20, 1968, at 56.

? See The True facts oN Firear.i Legtslation Thrte Statistical Stldies (National Shooting Sports Foundation, Inc., 1968).

sM. Wolfga.vg. Patteris in Crinisal Honicide (1958). "[F]ew homicides duc to shootings could be avoided merely if a firearm were not immediately present ... the offender would select some other weapon to achieve the same destructive goal. Probably only in those cases where a felon kills a police officer, or vice versa, would homicide be avoided in the absence of a firearm." Id. at 83. 
tion exceeded 100,000 in 1960. Differences in the other factors which may account for variations in the death and crime rates were obtained by collecting data relating to income, education, sex, police, race, population density, licensed hunters, age and temperature for the states and cities.

For the gun control legislation of the states and cities it was necessary to devise a method to measure the differences in state and city firearm legislation. Since there is a wide range of differences in weapons regulation among the states and cities, it was impossible to characterize adequately these differences by means of a dichotomous variable such as "weak gun control states" and "strong gun control states." It was possible, however, to classify the various gun control regulations into eight major categories. This permitted quantification of the gun control provisions of state statutes and city ordinances by assigning numerical weights to each of the eight categories in a manner to be explained below. Once gun control legislation was so quantified, a well-known data analysis technique was employed to obtain probabilistic estimates of the extent to which differences in the death and crime rates are related to the differences in gun control, while simultaneously accounting for other factors.

\section{Data}

The state death and crime data used in this study are 1960 and 1965 rates of homicide by firearm, total homicide, suicide by firearm, total suicide and accidental death by firearm and in addition, 1965 rates of robbery, aggravated assault by firearm and total aggravated assault; for cities, only 1960 rates for total homicide and total suicide were available. 5 In all instances the data are in rates per million population per year.

For states, the following explanatory variables were used: 1960 and 1965 income (thousands of dollars per capita); education (median school years completed by persons older than 24); sex (males per 100 females); police employees (employees per 10,000 population); race (non-white percentage of total population-1960, and black males per 50 population-1965); population density

\footnotetext{
the basic statistical technique used in this study was multiple linear regression. See notes. $48-51 \mathrm{in} / \mathrm{ra}$ and accompanying text. See generally $\wedge$. Goldobrakr. EcoNometric THt:ORY (1964).

- Sources of all data are available from the authors on request.
} 
(thousands of persons per square mile); age (median age in years) and licensed hunters (number per capita-1965 only).

For cities, the variables were: 1960 income (thousands of dollars per capita); education (median school years completed by persons older than 24); race (non-white percentage of population); population density (thousands of persons per square mile); age (median age in years); temperature (minus thousands of mean annual degree days$65^{\circ}$ base); $;^{6}$ manufacturing employees (persons per 1000 population employed in manufacturing durable goods); and police expenditures (dollars per capita)?

\section{Gun Control Legislation}

Federal legislation. Since we are concerned with variations in firearm legislation among states and cities, federal legislation is relevant orily to the extent that it sets minimum standards which exist throughout the United States. Prior to 1968, federal control over firearms was minimal: there were two federal statutes regulating the sale of firearms, both primarily aimed at the criminal purchaser. The National Firearms Act, ${ }^{8}$ enacted in 1934, restricted trade in machine guns and short-barreled shotguns and rifles by imposing a prohibitive tax on their manufacture and transfer, and by requiring manufacturers, importers, dealers and transferees of such weapons to register. The Federal Firearms Act of $1938^{\circ}$ extended federal control by requiring all firearm manufacturers, importers and dealers engaging in interstate commerce to obtain a federal license and to maintain permanent records of importation, shipment and other disposal of firearms; prohibited dealers and manufacturers from knowingly selling and delivering firearms to felons or to persons without a license to

\footnotetext{
- Mean annual degree days are calculated as follows: If the temperature is below $65^{\circ} \mathrm{H}$. subtract the temperature from 65 . If the temperature is above $65^{\circ}$, a value of zero is assigned. These daily averages are then added to determine the total number of degree days for the year. Thus, the colder the climate the greater is the number of mean annual degree days.

"For "States 1965", only 1960 age, education, race and police data were available. Data for all other explanatory variables were for the same year as the death and crime data.

${ }^{8}$ Ch. 757, 48 Stat. 1236 (1934). Presently codified as Pub. L. No. 90.618. \$201 (1968 U.S. CODE CONG. \& AD. NEwS 1413-24), amending 26 U.S.C. $\$ \$ 5801-5862$.

${ }^{3}$ Ch. 850, 52 Stat. 850 (repealed in 1968). The basic provisions of the Act are now contained in the Gun Control Act of 1968, Pub. L. No. 90-618, $\$ \$ 101-302$ (1968 U.S. CODE CONG. \& AD. News 1397-1424). This Act amended Title IV of the Omnibus Crime Control \& Safe Streets Act of 1968, Pub. L. No. 90-351, 18 U.S.C.A. §§ 921-28 (Supp. 1968), which had repealed the Federal Firearms Act of 1938.
} 
purchase where one was required by state or local law; and prohibited felons from receiving firearms and ammunition which had moved in interstate commerce. In addition, postal regulations prohibited shipments of hand guns through the mails, except between manufacturers and dealers and to certain public officers. ${ }^{10}$

In 1968 , stronger federal gun control legislation was enacted." ${ }^{11}$ Aimed at reinforcing state and local gun control regulations by barring interstate firearm transactions, the basic provisions of this Act include prohibitions against shipments of firearms in interstate commerce except between licensed dealers; ${ }^{\prime 2}$ prohibitions against persons, except licensed dealers, transporting into or receiving in the state of their residence any firearms obtained outside the state; $;^{13}$ prohibitions against sales to non-residents with certain exceptions for sales of rifles and shotguns to residents of a contiguous state; prohibitions against sales to or receipt by persons less than twentyone years of age (eighteen years of age for rifles and shotguns), convicted criminals, drug users and persons adjudicated as mentally defective; ${ }^{15}$ the imposition of licensing and record-keeping requirements on manufacturers, importers and dealers ${ }_{i}^{16}$ the imposition of controls over the manufacture, importation and sale of highly destructive weapons such as bazookas, mortars, grenades and bombs; $;{ }^{17}$ and the imposition of additional controls over weapons covered by the National Firearms Act. ${ }^{18}$

State and local legislation. There are substantial variations in state and local regulations over the sale, possession and use of firearms. States such as Ohio, ${ }^{19}$ Minnesota $^{20}$ and Kentucky ${ }^{21}$

10 39 C.F.R. 125.5 (1968). Prior to 1968 no restrictions were placed on interstate firearm shipments by common carrier. The chief effect of the postal regulations was to send the purchasers of handguns by mail to the Railway Express Agency rather than the post office.

"Gun Control Act of 1968, Pub. L. No. 90-618 $\$$ 101-302 (1968 U.S. CODE CONG. \& AD. NEwS 1397-1424), amending 18 U.S.C.A. \$\$ 901-28 (Supp. 1968).

12 Id. (1968 U.S. CODE CONG. \& AD. News at 1404-05) (18 U.S.C.A. \$§ 922(d), (I) \& (h)).

1s Id. (1968 U.S. CODE CONG. \& AD. NewS at 1401) (18 U.S.C.A. $\$$ 922(a)(3)).

"Id. (1968 U.S. CODE CONG. \& AD. NEwS at 1401-02) (18 U.S.C.A. \$ 922(a)(5)).

is Id. (1968 U.S. CoDE CoNG. \& AD. News at 1404) (18 Ü.S.C.A. $\$$ 922(d)).

${ }^{16}$ Id. (1968 U.S. CoDe CONG. \& AD. NEwS at 1406-09) (18 U.S.C.A. $\$ 923$ ).

I: Id. (1968 U.S. CODE CONG. \& AD. NEws at 1402, 1406.07) (18 U.S.C.A. $\$ \$$ 922(b)(4), 923(a)).

ix See note 8 supra and accompanying text.

19 Ohio Rey. Code ANN. $\$ \$ 2923.01-.06$ (Page 1954 \& Supp. 1968).

20 MiNs. STAT. ANN. $\$ \S 609.66-67$ (1964).

2! Ky. REy. StAT. ANN. \$ 435.230 (1963). 
impose almost no controls; while New Jersey, ${ }^{22}$ Hawaii $^{23}$ and Michigan $^{24}$ strictly regulate such activities.

The present study was limited to state and local laws regulating handguns, which are usually defined as firearms of less than three pounds and less than 12 to 20 inches. In addition, laws which regulate the use of firearms at particular times or places, laws which regulate the discharge of firearms, and laws which make the use of firearms in connection with other illegal conduct unlawful, were not considered. ${ }^{25}$ Table 1 lists the eight categories of gun control legislation used in the study and the states ${ }^{26}$ and cities $^{27}$ which have regulations in these categories. A city is shown within a category only if the state has no substantially equivalent regulation.

\section{TABLE 1}

State and City Gun Control Laws

\begin{tabular}{|c|c|c|c|c|c|c|c|c|c|c|}
\hline $\begin{array}{l}\text { STATE or } \\
\text { CITY }\end{array}$ & $a^{1}$ & $\begin{array}{c}2 \\
a b\end{array}$ & $\stackrel{3}{a} b$ & $a b$ & ${ }^{4} \mathrm{de}$ & 5 & $\begin{array}{c}6 \\
a b\end{array}$ & $\begin{array}{c}7 \\
a b\end{array}$ & 8 & $\begin{array}{l}\text { TOTAL } \\
\text { INDEX } \\
\text { VALUE }\end{array}$ \\
\hline Ala. & $x$ & & $x$ & & $\mathrm{x} x$ & $x$ & $x x$ & $x x$ & & 31 \\
\hline Alais. & $x$ & & & $x$ & $x x$ & & & & & 5 \\
\hline Ariz. & $x$ & & & $x x$ & & & & & & 4 \\
\hline Ark. & & $x$ & & & & & & & & 4 \\
\hline Cal. & $x$ & & & $x x$ & & $x$ & $\mathrm{X} x$ & $0 x$ & & 28 \\
\hline Colo. & $x$ & & & & & & $x$ & & & 10 \\
\hline Conn. & & $x$ & & $x 0$ & & $x$ & $x x$ & $x 0$ & & 29 \\
\hline Del. & $x$ & & & & $x$ & $\mathrm{x}$ & $\mathrm{x}$ & & & 20 \\
\hline Fla. & & $\pi$ & & $x x$ & & & & & & 6 \\
\hline Ga. & $\mathrm{x}$ & $\mathrm{x}$ & & $\mathrm{x}$ & & $\mathrm{x}$ & & & & 15 \\
\hline
\end{tabular}

z N.J. STaT. ANN. \$§ 2A:151-1 to $151-56$ (1953 \& Supp. 1968).

2 HaWAII REV. Laws $\$ \$ 157-1$ to -33 (1955).

${ }^{21}$ Mich. CoMp. Laws $\S \S 28.421-.434,750.222-.239$ (1967 \& Supp. 1968).

25 See, e.g., Conn. Gen. Stat. ANn. \$\$ 53-203, 53-204, 53-207 (1960); lowa COdE AN'N. $\S 110.23$ (1949); N.Y. Penal Law $\S 265.35$ (McKinney 1967).

${ }^{25}$ State data was obtained from Rosentrater. Sayli:s \& ConNi:R. State firearivs Control. a Conpilatiox of Digl:sts of Stati: Laws (Library of Cong. Legis. Reference Service, 1968). See also Note, Firearms: Problems of Control, 80 Harv. L. Rev. 1328, 1336-42 (1967); Note, Firearms Legislation, 18 VAND. L. Rev. 1362, 1366-69 (1965).

27 City data was obtained through correspondence with city solicitors. Replius were received from 94 citius. Of the 94 replies, 58 stated that there were no local firearms regulations. The other 36 replies either summarized or enclosed copies of local firearms regulations. Only 14 of the cities with regulations fitting within the categories of Table 1 were located in states which did not have similar regulations. 
TOTAL

$\begin{array}{lllllllllll}\text { STATE or } & 1 & 2 & 3 & 4 & 5 & 6 & 7 & 8 & \text { INDEX }\end{array}$ CITY $a b \quad a b \quad a b a b c d e \quad a b a b$ VALUE

Hawaii

Idaho

III.

Ind.

Iowa

Kan.

Ky.

La.

Me.

Md.

Mass.

Mich.

Minn.

Miss.

Mo.

Mont.

Neb.

Nev.

N. H.

N.J.

N. M.

N. Y.

N. C.

N.D.

Ohio

Okla.

Ore.

$\mathrm{Pa}$.

R. I.

S. C.

S. D.

Tenn.

Tex.

Utah

Va.

Wash.

Vt.

W. Va.

$\mathbf{x}$

$x \times x \quad x \quad x \times$

$\mathrm{X} \quad 35$

$$
x
$$

$x$

$x$

$x \times x$

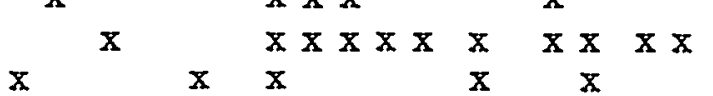

$\mathbf{x}$

$\mathrm{x} \times \mathrm{x} \times$

$\mathbf{x}$

$\mathrm{X}$

3

$x \quad x$

$x$

$\mathbf{X}$

$\mathrm{X} \mathrm{X}$

$\begin{array}{lllll}x \times x & x & x & x & 30\end{array}$

$\mathrm{x}$

$\begin{array}{lllll}x \times x & x & x & x\end{array}$

$\begin{array}{lllllll}x & x & x & x & \end{array}$

$\mathrm{x}$

$\mathrm{x} x \mathrm{x}$

$\mathrm{x} \times \mathrm{x} \times \mathrm{x} 26$

$\mathbf{x}$

$x \times$

4

$\mathrm{X}$

$x \mathbf{x}$

$\begin{array}{ll}x \times & 4 \\ x & 4\end{array}$

$x \quad x \quad x \times \quad x \quad x \times \quad 26$

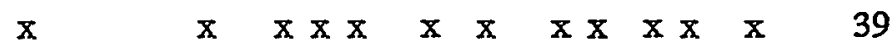

$\mathrm{x}$

X $x \times x \times x \times \quad x \quad 36$

$\begin{array}{lllll}x \times x \times x & x & x & 36 \\ x & x \times x \times & x \times & x & 27\end{array}$

$x \quad x \times x \times x \times 28$

$x \quad x$

$\mathrm{x} \mathrm{x}$

$x$

$x \quad x x \quad x \quad x \quad x$

27

$\mathrm{x}$

32

$\mathrm{x}$

$x \times x \times x x x x$

$x \quad \begin{array}{llllll}x \times x \times x & x & x & 28 \\ x & 0 & 0 & 0 & 0 & \end{array}$

$x \quad x \times \times \times \times x \times x \times 32$

$\begin{array}{llll}x & x \times x \times x & x & \end{array}$

$\mathrm{x} x \mathrm{x} \quad 6$

$x \quad x \quad x \quad 5$

$x \quad x \quad 3$

$x \quad x \times x \times x \times x \times 29$

Wis.

Wyo.

$\mathbf{x}$

$\mathbf{X}$

$x$

11 


\begin{tabular}{|c|c|c|c|c|c|c|c|c|c|c|}
\hline $\begin{array}{l}\text { STATE or } \\
\text { CITY }\end{array}$ & $a^{2} b$ & $\stackrel{2}{a b}$ & $a^{3} b$ & $a b$ & $\frac{4}{c d e}$ & 5 & $a^{6} b$ & $\begin{array}{c}7 \\
a b\end{array}$ & 8 & $\begin{array}{l}\text { TOTAL } \\
\text { INDEX } \\
\text { VACUE }\end{array}$ \\
\hline D. C. & & $x$ & & $x x$ & $x$ & $x$ & $x x$ & $x x$ & & 30 \\
\hline Duluth & $\mathrm{x}$ & & & & & $x$ & $x$ & & & 18 \\
\hline Jksnvl. & & & & & & & $x x$ & & & 12 \\
\hline K. C. (Mo.) & & $x$ & & & & & & & & 4 \\
\hline Louisv1. & & & & $x$ & & $x$ & $x$ & & & 13 \\
\hline Miami & & & & & $x x$ & & & & & 2 \\
\hline Mpls. & & & & & $x x^{\prime}$ & & $x$ & & & 7 \\
\hline Nashvl. & & & & & & & $x$ & & & 8 \\
\hline New Orl. & & & & & $x$ & & $x$ & & & 5 \\
\hline Okla. C. & & & & & $x$ & $x$ & $x$ & & & 13 \\
\hline Omaha & & & & & & $x$ & $x x$ & & & 20 \\
\hline Richmd. & & & & & & $x$ & $x x$ & & & 20 \\
\hline Tulsa & & & & & & & $x x$ & & & 12 \\
\hline $\begin{array}{l}\text { Wichita } \\
\times \text { All } \\
\text { o } 1965 \text { only }\end{array}$ & $x$ & & & & & & & & & 2 \\
\hline
\end{tabular}

1. Concealed a. license b. prohibition. 2. Carrying a. license b. prohibition .3. Carrying in Auto a. license b. prohibition. 4. Special Prohibitions on Possession a. minor b. felons c. addicts d. alcoholics e. mentally ill.5. Dealer Licensing. 6. Record Keeping a. by dealers $b$. by governmental agencies. 7. Waiting Period a. fixed time between purchase and delivery $b$. notification of authorities. 8. License to Purchase.

The first three categories of Table 1 reflect state and city laws regulating the carrying of handguns. The first category covers laws restricting the carrying of concealed handguns; the second covers laws restricting all carrying of handguns; and the third covers laws restricting the carrying of handguns in motor vehicles. ${ }^{28}$ Each of the categories is divided into two sub-categories-one listing states and cities which permit such activities by licensed parties and the other listing states and cities which totally prohibit such activities. ${ }^{29}$ In

\footnotetext{
${ }^{2 x}$ Category 3 (carrying-motor vehicle) includes only states and cities within category 1 (concealed) with laws which expressly restrict the carrying of firearms in motor vehicies. Category 3 does not include laws which generally prohibit the carrying of concealed weapons even though such laws may be construed to prohibit carrying concealed weapons in a motor vehicle, particularly if the weapon is within reach of occupants of the car. States within category 2 (carrying) usually prohibit the carrying of handguns on the person and in a motor vehicle.

${ }^{2}$ Generally, state and city laws within the first three categories of Table 1 exempt lawenforcement officers, military personnel, private guards and persons carrying firearms at their home or place of business. See, e.g., CAL. Penal CODE $\$ \S 12026-27$ (West 1956); New York is the only state which requires a license to possess a handgun in the home or place of business. N.Y. PeNal LAW $\$ \S 265.05(3), 400.00(2)$ (McKinney 1967).
} 
some states within the first sub-category, licenses to carry handguns are issued to all persons with the exception of felons, addicts, and minors..$^{30}$ Other states have requirements that the applicant be of "good moral character";";1 or that he show a need to carry the weapon. ${ }^{32}$ The issuing authority is usually a law-enforcement official, such as the chief of police..$^{33}$

Category 4, special prohibitions, lists five types of persons against whom additional restrictions are frequently imposed: felons, addicts, alcoholics, the mentally ill and minors. ${ }^{34}$ These restrictions usually prohibit transfers of handguns to, and ownership or possession by such persons. ${ }^{35}$

Dealer licensing, the fifth category, refers to the requirement that firearms dealers be licensed. ${ }^{36}$ Most of the statutes falling within this category impose licensing qualifications based on good character, age and a permanent business location, ${ }^{3 \pi}$ and thus

* See, e.g., Cal. PeNal COde $\$ \$ 12021,12050$, \& 12072 (West 1956) (license to carry may be issued to person of good moral character, but restrictions as to minors, addicts and felons); CONN. GEN. STAT. ANN. \$29-29 (1960) (no permit shall be issued if the applicant has evet been convicted of a felony); lowA CODE ANN. $\$ 695.26$ (Supp. 1968) (sale to minors forbidden).

"See, e.g., Cal. Peval Code $\$ 12050$ (West 1956); ME. Rev. Stat. AnN. tit. 25, \$2031 (Supp. 1967); N.Y. PENAL LAW $\$ 400.00$ (McKinney 1967).

z See, e.g. WASH. Rev. CODE ANN. $\$ 9.41 .070$ (1961) (for purposes of protection, or while engaged in business, sport or while traveling).

\# See, e.g., lowa CODE ANN. $\$ 695.20$ (1950); Wash. Rev. COde ANN. $\$ 9.41 .070$ (1961).

II Minors, as defined by the various states, range from persons under fourteen to persons under twenty-one. Also, some states exclude from the law's prohibitions minors with parental consent to purchase and possess firearms. Certain states limit restrictions against felons to persons who were convicted of crimes of violence within a specified time; restrictions against addicts to persons convicted under narcotics laws; restrictions against alcoholics to persons under the influence of alcohol; and restrictions against the mentally ill to persons committed for mental disorder. Other states either do not define these terms or use broader definitions. See generall. Note, Firearms: Problems of Control, 80 HARv. L. REv. 1328 (1967).

A state is within a sub-category of category 4 (Table 1) if it requires a license to purchase handguns and prohibits the issuance of such a license to persons covered by the subcategory. A state is not included within a sub-category of category 4, however, if it only prohibits persons within the sub-category from receiving a license to carry handguns.

is See CAL. Penal CODE $\$ \$ 12021,12072$ (West 1956).

see. e.g., N.Y. Penal Law \$ 400.00(1) \& (2) (McKinney 1967). A South Catolina law repealed in 1965 prohibited the sale but not the possession of handguns within the state. Since South Carolina was the only state to prohibit sales. Table 1 does not have a separate category to cover this type of restriction. Since category 5 appeared to be the most appropriate category, South Carolina was included therein.

'See N.Y. Penal Law \$ 400.00(1) (McKinney 1967). 
contain more restrictions than were imposed under the Federal Firearms Act. ${ }^{38}$ Under this Act dealer licenses were granted to anyone submitting a one dollar fee with an application stating that he was not a felon ${ }^{39}$

Under category 6 , record keeping, are listed the states requiring the maintenance of records of handgun sales. Sub-category (a) lists those states which require the dealer to keep such records; $;^{10}$ and subcategory (b) lists those states which require the dealer to file information concerning his handgun sales with governmental officialsusually a local law enforcement agency." The required records usually include the name and address of the purchaser, the date of the purchase and the description of the handgun, including its serial number.

Category 7 , waiting period, refers to a prohibition against the delivery of handguns for a specified time period after an application for purchase has been filed with the dealer. Listed in sub-category (a) are those states which impose any waiting period, the duration of which usually varies between one and fifteen days.2 Listed in subcategory (b) are those states having waiting periods which require the dealer to notify a law enforcement official of the application for purchase prior to delivery of the handgun..$^{43}$

The final category lists a requirement that the purchaser of a handgun obtain a license."4 Such licenses are usually issued by local law enforcement officers $s^{45}$ and persons are excluded from obtaining licenses for a wide variety of reasons. ${ }^{16}$ In several jurisdictions, ${ }^{, 7}$ law

¿x See note 9 supra and accompanying text.

${ }^{39}$ Hearings Before the Subcomm. to Investigate Juvenile Delinquency of the Senate Comm. on the Judiciary; 88th Cong., Ist Sess., pt. 14, 3209-10, 3426 (1963).

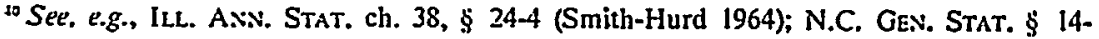
406 (1953).

"See. e.g., IOWA CODE AN.v. § 695.21 (1950).

12 See, e.g., Conn. Gen. Stat. ANN. \$ 29-33 (Supp. I969) (one week waiting period following mailing of application for purchase); ORE. REV. STAT. $\$ 166.470$ (1965) (fircarm shall not be delivered to purchaser on the day of the application for its purchase).

"See. e.g.v Wash. Rev. Code A.viv. $\$ 9.41 .070$ (1961).

"See, e.g., N.Y. Peval Law $\$ 400.00$ (McKinney 1967); N.C. GEN. Stat. \$14-402 (Supp. 1967).

is See, e.g., N.C. Gex. Stat. \$ 14-403 (Supp. 1967).

"s For an example of a statute which is very specific as to who may obtain a license to purchase, see N.J. STAT. ANN. \$\$ 2A:151-33 to 2A:151-39 (Supp. 1968). For a more "general" statute, see N.C. GEx. STAT. \$§ 14-402, 14-404 (Supp. 1967).

si See, e.g., N.J. Stat. Axis. \$ 2A:151-36 (Supp. 1968). 
enforcement officials have only a limited time to investigate the applicant.

Having categorized the gun control regulations, the next step was to quantify gun control legislation by assigning weights to each of the eight categories and summing the weights applicable to each state or city. Such a weighting procedure was necessary to permit the application of the multiple linear regression data-analysis techniqueds - the method used to analyze the differences in death and crime rates among the states and cities. Since some knowledge of multiple linear regression is essential to an understanding of the method of assigning numerical weights to the eight categories as well as to an interpretation of results, a brief description of the technique is presented at this time.

\section{Description of Data Analysis Technique}

Statistical methodology. The basic hypothesis of this study is that the variable of interest (e.g., the homicide rate) is a linear function of the selected independent variables (e.g., gun control index, income, population density) and a random error term. That is,

$$
Y_{i}=B_{0}+B_{1} X_{1 i}+B_{2} X_{2 i}+\ldots+B_{k} X_{k i}+U_{i} \quad i=1,2, \ldots, n
$$

where

$$
\begin{aligned}
& Y_{i}= \text { value of the dependent variable }(e . g ., \text { homicide rate) } \\
& \text { for the } i \text { th city or state; } \\
& {\left[X_{1 i},\right.}\left.X_{2 i}, \ldots, X_{k i}\right]=\text { set of values of the } k \text { independent } \\
& \text { variables (gun control index, etc.) for the } i \text { th } \\
& \text { city or state; } \\
& {\left[B_{0}, B_{1}, \ldots, B_{k}\right]=\text { set of unknown coefficients which we wish } } \\
& \\
& \text { to estimate; } \\
& \mathrm{U}_{i}= \\
& \text { random ermor term for the ith city or state. This } \\
& \text { includes both truly random (not related to the independent } \\
& \text { variables) variation and the effect of any omitted } \\
& \text { variables; and }
\end{aligned}
$$

\footnotetext{
"* For a description of multiple linear regression, see J. JohNston. ECoNometric Methods 106-42 (1960).
} 
$\mathrm{n}$ = sample size (the number of states or cities in the sample).

The unknown coefficients, $\left[B_{0}, B_{I}, \ldots, B_{k}\right]$, are estimated by the method of least squares. That is, that set of estimates is chosen,

$\left[\hat{\mathrm{B}}_{0}, \hat{\mathrm{B}}_{1}, \ldots, \hat{\mathrm{B}}_{k}\right]$, which makes the sum of squared emons,

$$
\sum_{i=1}^{n} \hat{\mathrm{U}}_{i}^{2}=\sum_{i=1}^{\mathrm{n}}\left(\mathrm{Y}_{i}-\hat{\mathrm{Y}}_{i}\right)^{2}=\sum_{i=1}^{\mathrm{n}}\left(\mathrm{Y}_{i}-\hat{\mathrm{B}}_{0}-\hat{\mathrm{B}}_{1} \mathrm{X}_{1 i}-\hat{\mathrm{B}}_{2} \mathrm{X}_{2 i}-\ldots-\hat{\mathrm{B}}_{k} \mathrm{X}_{k i}\right)^{2},
$$

as small as possible. 49

The estimated total variance of $Y$ is defined as

$s_{y}^{2}=\sum_{i=1}^{n}\left(Y_{i}-\bar{Y}\right)^{2} /(n-1)$ where $\bar{Y}=\sum_{i=1}^{n} Y_{i} / n$.

The estimated unexplained variance is $s_{u}^{2}=\sum_{i=1}^{n} \hat{U}_{i}^{2} /(n-k-1)$. Therefore, $s_{u}^{2} / s_{y}^{2}$ is the fraction of the total vaniance of $Y$ not explained by the regression.

An estimate of the uncertainty associated with a particular estimated coefficient may be obtained by computing the ratio of the estimated coefficient to the square root of its estimated variance. From this ratio the probability of sign error (assuming the errors are normally and independently distributed), which is the probability that the true coefficient is negative (positive) if the estimated coefficient is positive (negative), is computed. ${ }^{50} \mathrm{~A}$ related measure, the $95 \%$ confidence interval, is also reported. In nonstatistical terms, there is a $95 \%$ probability that the true coefficient falls within this interval.

ln addition to information about the individual coefficients, a

19 $I d$. at $108-09$.

so "Probability of sign error" is not the conventional interpretation of the numbers given here. They are usually termed "levels of significance," and the interpretation of them is somewhat different. The terminology used herein results from a Bayesian approach to the regression problem in which the parameters are considered random variables. The prior distributions which the authors have implicitly used here are locally uniform probability measures. 
measure of the overall adequacy of the assumed relationship is desirable. This is provided by

$$
\overrightarrow{\mathrm{R}}^{2}=1-\mathrm{s}_{\mathrm{u}}^{2} / \mathrm{s}_{\mathrm{y}}^{2},
$$

which measures the fraction of the variance of $Y$ "explained" by the regression. ${ }^{51}$

Quantifying gun control legislation. One may have some intuitive feelings about the relative effectiveness of the various categories of gun control regulations listed in Table 1. Since opinions of this subject may vary substantially, however, numerical weights should be assigned to these categories on some basis more reliable than intuition. In the present study approximately thirty sets of weights were selected which displayed great variation in the relative importance of the eight different categories. For each death and crime rate thirty regressions were then computed. Since other explanatory variables were held constant for all thirty regressions, the only difference among the regressions was that each had a different index for gun control as an explanatory variable.

For a given death or crime rate the best index would be that which yielded the maximum value of $\overline{\mathrm{R}}^{2}$, or, equivalently, the smallest probability of sign error in the estimated gun control coefficient. This index explains the greatest amount of variation in the death or crime rate, having accounted for other explanatory variables.

Selection of the set of weights in this manner does not bias the results either in favor or against gun control. it simply chooses those weights which have the highest probability of measuring the true relative effects of various gun control laws, whether those true effects be positive, negative or null. For example, suppose that license to purchase legislation were twice as effective in reducing homicides as concealed weapons legislation. This would mean that part of the variation in homicide rates among the states is due to some states having none, some one, and some both of these laws. Our objective is to account for the homicide variation among the states and cities and, of course, the highest percentage of the variation will be explained by the set of weights that exactly

\footnotetext{
${ }^{3}$ The number is $R^{*}$ adjusted for degrees of freedom. See $A$. GoLDBl:RGkR. f:CoNonetric THEORY 217 (1964).
} 
matches the true cause of the variation. Reasoning backwards, this means that the index with the highest $\bar{R}^{2}$ is most likely to be composed of the set of weights that most closely matches the true relative effect.

None of the thirty indices selected consistently produced the highest $\bar{R}^{2}$ for the various regressions. Different indices performed better for different deaths and crimes. This is shown in Table A-2 of the Appendix which reports the estimated gun control coefficient and its probability of sign error for ten different indices which were selected to show substantial but systematic variation. However, while the magnitude of the effect of gun control legislation varied with the index chosen, the direction of the effect was (except for aggravated assaults by firearm and robbery) independent of the index chosen, ${ }^{52}$ and thus inferences as to the effectiveness of gun control legislation may be made with confidence.

Results from the use of index 4 of Table A-2, the index which yielded the highest $\bar{R}^{2}$ in the greatest number of death categories considered (five out of twelve), are reported in the text. This index is listed in Table 2. In terms of estimating the number of lives saved by gun control legislation, however, this index ranked seventh out of the ten reported in the Appendix. Another index, number 3, yielded the highest $\mathrm{R}^{2}$ for four death categories and gave the highest estimate of the number of lives saved by gun control..$^{53}$

\section{TABLE 2}

Weights of Gun Control Legislation Categories

(Index 4)

Legislative Category

1. Concealed

License Numerical Weight

Prohibition

2

2

2. Carrying

License

Prohibition

4

4

3. Carrying in Auto

License

2

Prohibition

2

\footnotetext{
: See Appendix, Table A-2.

F Set 4 best explained homicide by firearm, (i.e., had the highest $\bar{R}^{2}$ ), and total homicide for the states (1960\& 1965), and accidental death by firearm (1965). Set 3 best explained suicide by firearm for the states (1960\& 1965), total suicide (1960), and accidental death by firearm (1960).
} 
4. Special Prohibitions Minors 1

Felons 1

Addicts 1

Alcoholics 1

Mentally III 1

5. Dealer Licensing 8

6. Record Keeping By Dealers 8

By Government Agency 4

7. Waiting Period Time 1

Notice 2

8. License to Purchase 8

The text also reports the effects of other explanatory variables on death and crime rates. These coefficients do not vary substantially with different gun control indices.

\section{RESULTS OF THE STUDY ${ }^{54}$}

Results of the study are stated in terms of estimated coefficients which set forth the relationship between the various independent variables and the death and crime rates. Each coefficient indicates the estimated extent to which a one unit increment in an independent variable (e.g., gun control) will affect the dependent variable (a death or crime rate).

There is some uncertainty associated with the value of the estimated coefficient. As previously indicated, two measures were utilized to determine the degree of uncertainty: the $95 \%$ confidence interval and the probability of sign error..$^{j 3}$

\section{Homicide}

The relationship between gun control and homicide by firearm and total homicide rates in the states and cities for 1960 and 1965

\footnotetext{
${ }^{3}$ The material appearing in the Results section ate based upon the use of the set of weights for the various categories of gun control legislation listed in Table 2 (Index 4).

is The $95^{\circ}$ confidence interval is the range within which there is a .95 probability that the true coefficient will lie. The probability of sign error, as previously indicated, reflects the chance that the sign of the estimated coeflicient is incorrect.
} 
is given in Table $3 .{ }^{56}$ The data in Table 3, presented in terms of the effect which a one unit increment in gun control will have on homicide rates, indicate that gun control probably has a negative effect on homicide by firearm and total homicide rates. In all five sets of equations the estimated gun control coefficient is negative and in only one case is there more than a fifteen percent chance that the coefficient's sign is positive (see total homicide rate for "States-1965" - Probability of Sign Error).

\section{TABLE 3}

EFFeCt of GUN CONTROL on Homicde

Homicide Rate

(Deaths/million/year)

By Firearm

States-1960
States-1965

Total

States-1960

States-1965

Cities-1960

$\begin{array}{ccc}95 \% \text { Confidence } & \begin{array}{c}\text { Probability } \\ \text { Interval }\end{array} & \text { of sign error }\end{array}$

.113

.0602

Table 4 presents the relationship of each of the independent variables to the death and crime rates. The results in Table 4 show that median income and population density are negatively related to homicides by firearm and total homicides; that the percentage of males, the number of police employees and the percentage of nonwhites have strong positive relationships with homicide rates; and that the correlation between education and homicide was negative in 1960 and positive in 1965.

\footnotetext{
${ }^{36}$ All relationships reported in this study are conditional because the effects of other demographic variables are taken into account.
} 


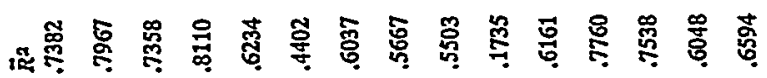

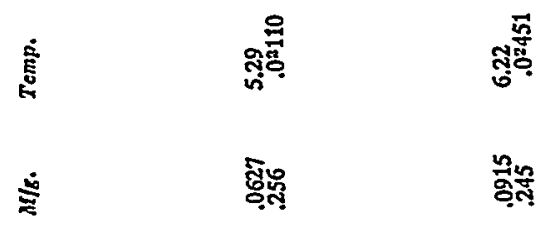

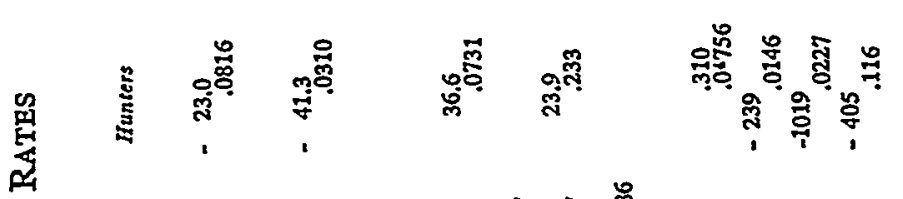

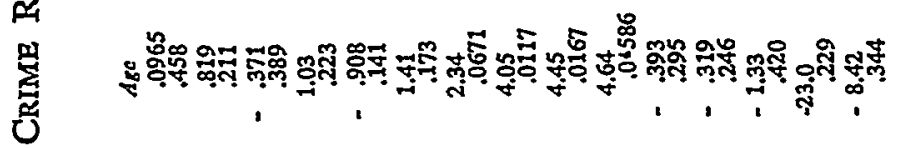

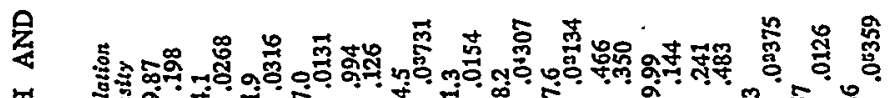

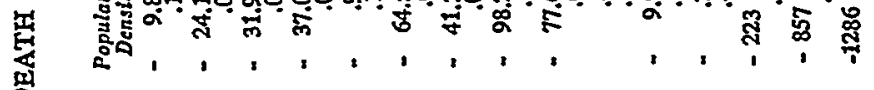

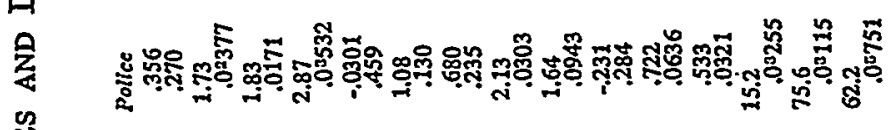

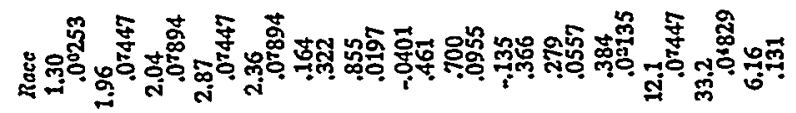

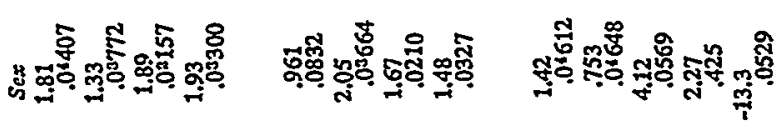

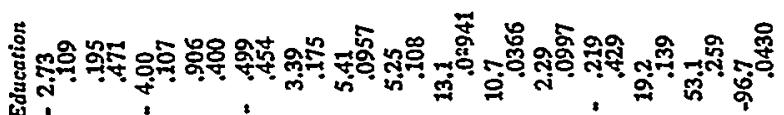
兽

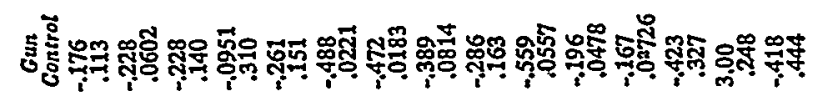

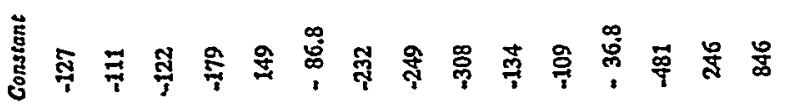

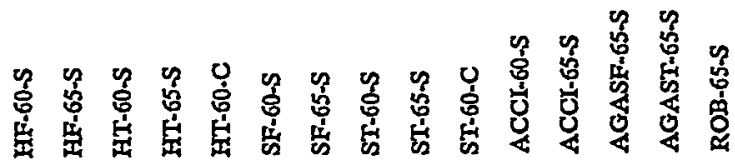




\section{Suicide}

Table 5 reports the relationship between gun control and suicide by firearm and total suicide rates. For all five equations the sign of the estimated gun control coefficient is negative, significant and sizeable. For four of the five equations there is a less than ten percent probability that the sign is incorrect. In comparison with the results for total homicide, there is a much greater probability that the gun control coefficient of total suicide is negative and of a greater magnitude-the estimated gun control coefficients of total suicide are approximately twice as large.

TABLE 5

EFFECT OF GUN CONTROL ON SUICIDE

Suicide Rate

(Deaths/million/year)

By Firearm

States-1960

States-1965

Total

\begin{tabular}{|c|c|c|c|c|}
\hline States-1960 & -.389 & -.940 to & .163 & .0814 \\
\hline States-1965 & -.286 & -.866 tc & .295 & .163 \\
\hline Cities-1960 & -.559 & -1.25 tc & .131 & .0557 \\
\hline
\end{tabular}

95\% Confidence

Interval

-.962 to $-.0132 \quad .0221$

-.913 to $-.0309 \quad .0183$

$-.488$

$-.472$
Under the heading Suicide-by-Firearm (SF) in Table 4, it can be seen that the number of years of school completed, median age, the number of licensed hunters, average temperature and the percentage of males have strong positive relations with suicides by firearm while population density has a strong negative relation. There is also an indication that median income is negatively related to suicides by firearm but not to total suicides.

\section{Accidental Deaths by' Firearm}

Table 6, which shows the relationship between accidental deaths by firearm and gun control, indicates that the estimated gun control coefficients of accidental death by firearm are as significant (in terms of confidence interval and probability of sign error) as the suicide coefficients but only about the size of the homicide coefficients. 
TABLE 6

Effect of Gun Control on Accidental Death by Firearm

Accidental Death Rate

(Deaths/million/year)

States-1960

States-1965

$95 \%$ Confidence
Coefficient
Interval

$-.196$

$-.167$
Probability

of sign error

.0478

.0072

The relationship between accidental deaths by firearm and other variables as shown in Table 4 indicates that the only significant negative factor is income. Significant positive factors include the percentage of males, the percentage of non-whites, the number of police employees and the number of licensed hunters.

\section{Aggravated Assaults}

In Table 7 the relationship between gun control and aggravated assault is presented. There is a $67 \%$ probability that gun control is associated with a lower number of aggravated assaults by firearm (since the probability of sign error is .327), and about a $75 \%$ probability that gun control is related to a higher total of aggravated assaults (probability of sign error is less than .25).

Table 4 indicates that low income, a high percentage of nonwhites, a high number of police employees, lower population density and fewer licensed hunters are associated with a higher number of aggravated assaults.

\section{TABLE 7}

Effect of Gun Control on Aggravated Assault

Aggravated Assault Rate

(Assaults/million/year)

Coefficient

States-1965

By Firearm

Total

$-.423$

3.00

\section{5\% Confidence}

Interval

-2.32 to 1.47

-5.82 to 11.8
Probability

of sign error

.327

.248

\section{Robbery}

The relation between robbery and gun control is set out in Table 8. The estimated gun control coefficient indicates that one unit of gun control will reduce the total number of robberies by less 
than one half robbery per million population per year (or about 100 fewer robberies per year in the U.S.) and that there is only a $56 \%$ chance that the coefficient's sign is correct.

\section{TABLE 8}

\section{EFFECT OF GUN CONTROL ON ROBBERY}

$\begin{array}{cccc}\begin{array}{c}\text { Robbery Rate } \\ \text { (Robberies/million/year) }\end{array} & \text { Coefficient } & \begin{array}{c}95 \% \text { Confidence } \\ \text { Interval }\end{array} & \begin{array}{c}\text { Probability } \\ \text { of sign error }\end{array} \\ \text { States-1965 } & -.418 & -6.38 \text { to } 5.55 & .444\end{array}$

Returning to Table 4, robbery is shown to be negatively related to education, population density, licensed hunters and the percentage of males; and positively related to income, the number of police employees and the percentage of non-whites.

\section{Observations}

The following observations may be drawn from the data presented in the previous section.

One: The data indicate that gun control legislation is related to fewer total deaths by homicide, suicide and accident by firearm. The estimated gun control coefficient is negative in the five homicide equations, the five suicide equations and both accidental death by firearm equations. Moreover, in seven of these twelve equations the probability of error is less than ten percent and in only one of the equations does it exceed seventeen percent (total homicides-States $-1965-31.0 \%)$.

The estimated gun control coefficients of total homicide, total suicide and accidental death by firearm for the states in 1960 were $-.228,-.389$ and -.196 , respectively; and for the states in 1965 were $-.095,-.286$ and -.167 , respectively. On the basis of these results it is estimated that one unit of gun control saves between .548 and .813 lives per million population per year. Thus it can be estimated that the gun control legislation of New Jersey ( 39 units) saves between 21 and 32 lives per million population per year. On a nationwide basis such legislation would save between 4200 and 6400 lives per year..$^{5 \pi}$

\footnotetext{
${ }^{5}$ The estimates on lives saved include lives already saved by existing gun control legislation. In 1965 in the United States there were approximately, per 100,000 population.
} 
The average index value (simple arithmetic mean) of gun control for the states in 1965, using the weights contained in Table 2, was 17.5. If all 28 states whose indices were below 17.5 were brought up to that number, an estimate based on the results of this study would indicate that about 505 fewer lives per year would be lost due to homicide, suicide and accidental death by firearm in those states. Furthermore, if all states were raised to the 39-units level of New Jersey, about 1950 lives would be saved.

Two: A comparison of the results of the homicide and suicide by firearm rates with the total homicide and suicide rates provides an indication of the extent to which gun control legislation leads to the successful substitution of other weapons. ${ }^{58}$ The similarity of the estimated gun control coefficients of homicide by firearm and total homicide for $1960(-.176$ and -.228$)$ and of suicide by firearm and total suicide for $1960(-.488$ and -.389$)$ would support a conclusion that other weapons are not successful substitutes for firearms. However, the differences between the estimated gun control coefficients of homicide by firearm and total homicide for 1965 (-.228 and -.0951$)$ and of suicide by firearm and total suicide for 1965 ( -.472 and -.286$)$, would lead one to believe that other weapons are frequently and successfully substituted for firearms.

The results showing a $75 \%$ probability that the gun control coefficient of total aggravated assaults is positive give some indication that more stringent gun control laws tend to cause the use of less effective weapons rather than to discourage homicide attempts. One explanation for the positive relation is that the additional aggravated assaults which occur in stringent gun control states are homicide attempts which are unsuccessful as a result of the use of less lethal substitutes. This explanation, however, can only account for part of the large (3.00) gun control coefficient for total aggravated assaults.

Another explanation for the positive relation is that the felon armed with a gun, assuming that he is responsible for a significant portion of the aggravated assaults, has less need to use force to

3.05 homicides by firearm, 5.5 total homicides, 5.02 suicides by firearm, 11.1 total suicides, and 1.2 accidental deaths by firearm. See 1967 Statistical ABstract of tHe UNITED States 59, 168 (U.S. Dep't of Commerce).

${ }^{x}$ In Zimring, Is Gun Coutrol Likely to Reduce Violent Killings? 35 U. CHI. L. Rev. 721 (1968), the author describes a study measuring the effectiveness of substituted weapons based on data from reported homicides and serious assaults. 
obtain the victim's cooperation and to effect his get-away and that in stringent gun control states the hardened criminal is less likely to be armed with a gun and hence more likely to use force..$^{59}$

Three: The evidence indicates that gun control has little effect on "ordinary" crime. As mentioned previously, there is a positive estimated relation between total aggravated assaults and gun control; and while for robbery the estimated gun control coefficient is negative (-.418), there is a forty-four percent chance that the coefficient's sign is incorrect. Moreover, even if the estimated coefficient is correct, the enactment of strict gun control legislation will not substantially reduce the robbery rate which exceeded six hundred robberies per million population for the nation in 1965 .

Four: Results for other variables show that with the exception of robbery and total suicide, there is a negative correlation between income and the death and crime rates considered by this study; that education as measured by median school years completed is an important factor only for suicides (positive correlation) and robbery (negative correlation); that with the exception of robbery the relation between the percentage of males and the death and crime rates is strongly positive; that with the exception of suicide-1960, there is a strong positive relation between the percent of non-whites and the death and crime rates; that the relation between population density and the death and crime rates is strongly negative; and that the relation between the number of police personnel per capita and the death and crime rates is generally positive.00

\section{LIMITATIONS}

One: As previously indicated, certain types of state and local gun control legislation were not considered; the comparison between the states did not take into account the additional gun regulations of local governments within the state; and the gun control categories of Table 1 contain within the same category laws

\footnotetext{
${ }^{59}$ A third explanation for the direct relationship between gun control and aggravated assaults is that stringent regulation of weapons increases crime by redueing the number of persons possessing firearms for protection. However, the findings on robbery (see Table 8 and the textual discussion appurtenant thereto) are not consistent with such an explanation.

${ }^{60}$ Significant positive coefficients for the number of police personnel is not necessarily indicative of a causal relationship. Another explanation is that states and cities with high death and crime rates employ more police personnel in an attempt to reduce these rates, but that such additions to police forces are not significantly effective.
} 
which differ to some extent. Since the evidence derived from this study indicates that additional gun control reduces the number of deaths, this has probably caused the effects of gun control legislation to be understated.

Two: The data used by this study do not account for differences in the enforcement policies of the different states and cities and for inaccurate reporting of deaths and crimes.

Three: The coefficients of certain demographic variables may not indicate a causal relation. The ecology of crime is more complex than this study's simple equations portray. The relation between the number of police personnel per capita and the death and crime rates illustrates this point.

Also, it is possible that important explanatory variables have been omitted. Two that are frequently mentioned in $\mathrm{FBl}$ reports are the number of transient residents and the penalty ordinarily imposed for the crime committed. Others that may be important include regional differences in attitudes towards firearms, regional religious differences, differences in levels of frustration and differences in racial attitudes. ${ }^{61}$

Four: Since as of 1965 no state or city had totally prohibited the sale and possession of hand guns or imposed strict regulations on the sale and possession of rifles, the study tells little about the effectiveness of such types of gun control regulation. On the basis of this study's findings that additional controls, meaning increased units of gun control, reduce the homicide, suicide and accidental death by firearms rates, it would be expected that more stringent gun control, such as the regulation of rifles and the total prohibition of sale and possession of hand guns, would lower these death rates-but to what extent it cannot be said.

Also, this study does not indicate whether more stringent types of gun control would reduce "ordinary" crime. Perhaps measures

"In a separate tabulation, a dummy variable for the eleven states which formed the Confederacy was included. Results obtained indicated that homicides and aggravated assault rates are positively related to these eleven states; that accidental death by firearm is negatively related to these states; and that robbery and suicide are unrelated to these states.

These results do not weaken the conclusions of this paper concerning the effectiveness of gun control because the stringency of gun control legislation in the eleven Confederate states and in the remaining states is not dissimilar. The mean index value of gun control legislation for the fifty states based upon the set of weights reported in the text was 17.5. In comparison, for the eleven Confederate states the mean index value was 14.2, and for the seven Confederate states with the highest homicide rate the mean index value was 16.6 . 
such as prohibitions against the manufacture, sale and possession of all or certain types of firearms would disarm the professional criminal, and perhaps the disarmed professional criminal would be more hesitant to engage in criminal activity.

Five: While this study concludes that increases in the units of gun control decrease rates of homicide, suicide and accidental death by firearm, it does not show whether all unit increases in the amount of gun control are equally effective. It may be that the extent of the effectiveness of an increased unit of gun control is related to the amount of gun control which already exists within the state or city, or that certain types of gun control are effective only if other types of gun control are also enacted.

Six: The percentage of explained variation $\left(\bar{R}^{2}\right)$ in the death and crime rates was very similar for index weights that differed considerably from the weights listed in Table 2. Thús uncertainty remains as to the relative importance of the different types of laws.

\section{CONCLUSION}

The finding of the present study that gun control legislation reduces the number of deaths by homicide, suicide and accidents by firearm is inconsistent with three related research papers by Alan S. Krug which have received important circulation. Each of Krug's papers has been introduced into the Congressional Record, and the papers are presently being circulated in pamphlet form by the National Shooting Sports Foundation under the billing of "the first comprehensive study on a national basis ever made on the relationship of firearms to crime in the United States." ${ }^{\text {62 }}$

Each of Krug's papers claims to discredit the position that gun control legislation reduces crime. In his first paper, Krug reports that the homicide by firearm rate has shown a decided downward trend from 1910 to 1967 while gun ownership has steadily risen ${ }^{63}$ In a second paper a simple comparison is developed which shows no significant differences between the crime rates of states with and states without firearm licensing laws. ${ }^{64}$ The third paper reports a

62 The True Facts on Fireari Legislation-Three Statistical Studies (National Shooting Sports loundation, Inc., 1968), 114 CoNG. ReC. H570 (Jan. 30, 1968) [hereinafter cited as TRUe FACTS]. See Zimring, Games with Guns and Statistics, 1968 Wis. L. Rev. 1113.

- Krug, The Misuse of Firearms in Crime, in TRUE FACTS.

c Krug. The Relationship Between Firearms Licensing Laws and Crime Rates, in TRUE FACTS. 
negative correlation between firearm ownership, as measured by the number of hunting licenses, and various crime rates for the fifty states. ${ }^{65}$

Krug's second study is of primary interest here since it, like the present study, compares differences in crime rates among states with differences in gun control legislation. In this paper, Krug first places the states into two groups: licensing and non-licensing states. Next, using 1965 data, Krug calculates average (arithmetic mean) homicide, robbery, aggravated assault and serious crime rates for licensing and non-licensing states and finds that the average homicide, aggravated assault and serious crime rates for licensing states exceeded the non-licensing states' average.

As a vehicle for discrediting gun control legislation, this study by Krug has several major deficiencies. First, the only death rate it considered was the homicide rate by firearm, and, as Krug admits in another section of the same study, this accounts for less than onethird of the nation's deaths by firearm. ${ }^{66}$ Thus the conclusion that licensing has no effect on the homicide rate does not discredit a position that licensing reduces death by firearm.

Second, by using only two groupings for the fifty states and by examining only licensing requirements, the True Facts study failed to account for differences in state licensing requirements or other statutory controls over firearms. Moreover, by including within the licensing group any state which prohibits carrying firearms without a license, the licensing category included many states with weak gun control legislation. The legislation of six of the thirty-six states Krug included as licensing states had an index value of seven or less on the basis of the criteria used in the present study, while four of the fourteen states included as non-licensing states had an index value of seven or more.

Finally, although Krug recognized that factors such as population density, geography, per capita income and education appear to be significantly related to crime rates, these factors were completely neglected in his "statistical study." Thus, for these reasons it is submitted that the evidence presented in this study invalidates conclusions concerning death rates presented in these earlier papers.

\footnotetext{
कs Krug, The Relationship Between Firearns Ownership and Crime Rates: A Statistical Analysis, in TRUE FACTS.

"see note 57 supra.
} 
Krug's other studies conclude that there is no relationship between the number of firearms and crime rates. These conclusions are of dubious merit for the reasons stated in an in-depth analysis of the Krug studies by Franklin E. Zimring. ${ }^{67}$ Professor Zimring criticizes the first study, which examines the homicide by firearm and gun ownership trends, because (a) Krug's assertion that the homicide by firearm rate has shown a decided downward trend is questionable; (b) Krug failed to establish that per capita gun ownership is rising - he asserted only that the number of guns owned is rising; and (c) Krug's findings, even if accurate, do not preclude the possibility that stringent gun control legislation would have further reduced the homicide by firearm rate. Krug's third study, which finds a negative correlation between gun ownership and various crime rates for the fifty states, is criticized by Zimring for the use of hunting licenses as a measure of firearm ownership. Zimring asserts that hunting is not the major use of firearms in many areas of the nation or the major use of handguns, the weapons most frequently used in crime.

Nevertheless, even if Krug's conclusion that there is no relationship between the number of guns and crime rates should be correct, this in itself does not establish that gun control laws are ineffective. Most firearm legislation, according to its proponents, is not aimed at and does not prevent the law-abiding citizen from acquiring firearms. Rather, the legislation's purpose and effect is to keep guns out of the hands of minors and irresponsible adults.

This article has made no attempt to explain why gun control legislation reduces the number of deaths by firearm. To the authors' knowledge there is no reliable data on gun ownership, and hence it is not possible to agree with or dispute the thesis that there is no relationship between the number of guns and the death and crime rates. The findings here do indicate, however, that gun control legislation is most effective in reducing the number of suicides and accidents by firearm, less effective in reducing the number of homicides and generally ineffective in reducing the number of other crimes-all of which suggests that stringent gun control legislation reduces the number of persons possessing firearms. It seems likely that a high percentage of suicides, accidents by firearm and homicides are committed by adults who have never been convicted of a crime,

"Zimring, Games with Guns and Statistics, 1968 WIS. L. REv. 1113. 
adjudged mentally incompetent, or designated an addict or alcoholic. ${ }^{68}$ Thus the most plausible explanation for the effectiveness of gun control in reducing these death rates is that the percentage of adults who could lawfully obtain firearms is reduced by stringent gun control legislation.

The concern of this study is with the effectiveness of gun control legislation. On this point evidence is presented that stringent gun control legislation reduces death by homicide, suicide and accidents by firearm. For each of ten varying sets of weights reported in the Appendix, the gun control coefficients of homicide, suicide and accidental deaths by firearm are negative. Thus the conclusions do not depend upon our choice of weights. The choice of weights does, however, make a difference as to the size of the gun control coefficients. Results based on the ten sets of weights reported in the Appendix ranged from 1520 to 3340 additional lives saved if all states were raised to the level of New Jersey ${ }^{69}$ Consequently, there is no doubt that gun control legislation saves lives but there is a question of how many lives it saves.

ax During 1965, 79\% of all murder victims were acquainted with the offender. Killings resulting from robberies, sex motives, gangland slayings, and other felonious activities accounted for only $16 \%$ of the total of reported homicides. See RePORT BY THE PRESIDENT'S Comihission on Law Enforcenient and Aditnistration of Justice. The Challenge of CRIME IN A Free SOCIETY 39 (1967).

"The index reported in the text, number 4 , ranked seventh out of ten in terms of estimated total lives saved. 


\section{APPENDIX}

Further-Results

As mentioned in the text, we tried ten different sets of weights, each set yielding a different gun control index. These weights are given in Table A-1. Table A-2 lists for each index the gun control coefficient and the probability of its sign error for each crime or death rate.

\section{TABLE A-1}

\section{WEIGHTS FOR THE TEN GUN CONTROL INDICES}

\section{Index}

\section{$\begin{array}{lllllllllll}\text { Legislative Category } & 1 & 2 & 3 & 4 * & 5 & 6 & 7 & 8 & 9 & 10\end{array}$}

1. Concealed
a. License
b. Prohibition

$\begin{array}{llllllllll}2 & 2 & 2 & 2 & 2 & 5 & 2 & 5 & 5 & 2\end{array}$

$\begin{array}{llllllllll}2 & 2 & 2 & 2 & 2 & 5 & 2 & 5 & 5 & 2\end{array}$

2. Carrying
a. License
b. Prohibition
$\begin{array}{llllllllll}4 & 4 & 4 & 4 & 4 & 10 & 4 & 10 & 10 & 4\end{array}$
$\begin{array}{llllllllll}4 & 4 & 4 & 4 & 4 & 10 & 4 & 10 & 10 & 4\end{array}$

3. Carrying in Auto
a. License
$\begin{array}{llllllllll}2 & 2 & 2 & 2 & 2 & 5 & 2 & 5 & 5 & 2\end{array}$
b. Prohibition

$\begin{array}{llllllllll}2 & 2 & 2 & 2 & 2 & 5 & 2 & 5 & 5 & 2\end{array}$

4. Special Prohibitions
a. Minors
b. Felons
c. Addicts
d. Alcoholics
e. Mentally III
$\begin{array}{llllllllll}1 & 1 & 1 & 1 & 1 & 1 & 8 & 1 & 8 & 8 \\ 1 & 1 & 1 & 1 & 1 & 1 & 8 & 1 & 8 & 8\end{array}$
$\begin{array}{llllllllll}1 & 1 & 1 & 1 & 1 & 1 & 6 & 1 & 6 & 6\end{array}$
5. Dealer Licensing
$\begin{array}{llllllllll}2 & 2 & 2 & 8 & 8 & 2 & 2 & 8 & 2 & 8\end{array}$

6. Record Keeping
a. By Dealer
b. By Govt. Agency
$\begin{array}{llllllllll}2 & 2 & 2 & 8 & 8 & 2 & 2 & 8 & 2 & 8 \\ 2 & 2 & 2 & 4 & 4 & 2 & 2 & 4 & 2 & 4\end{array}$

7. Waiting Period
a. Time
b. Notice
8. License to Purchase $\quad \begin{array}{llllllllll}8 & 4 & 12 & 8 & 4 & 8 & 8 & 8 & 8 & 8\end{array}$

*This index was reported in the text. 


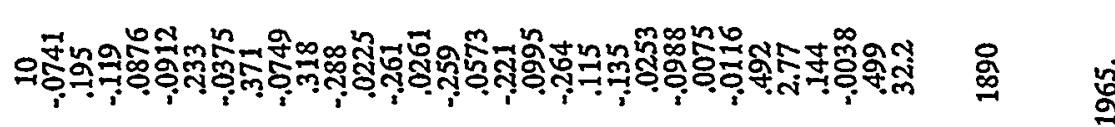

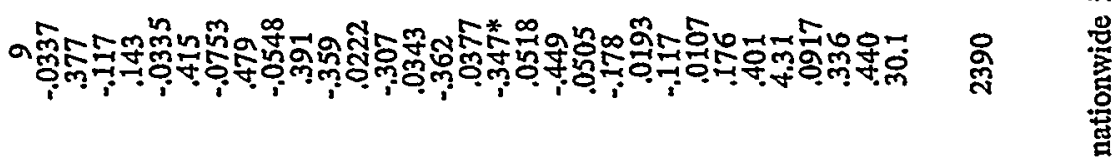

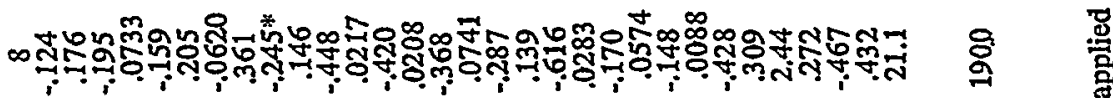

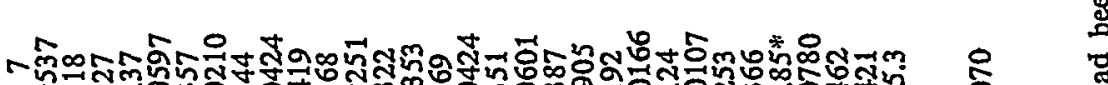

ㅇำ

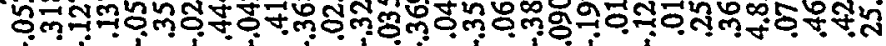

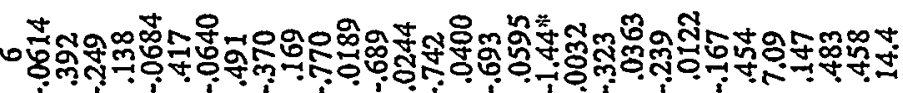

웅

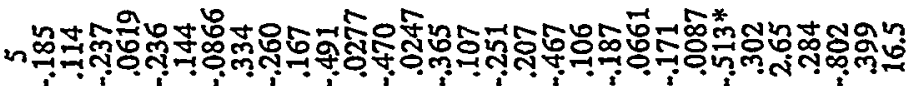

욕 总

눈

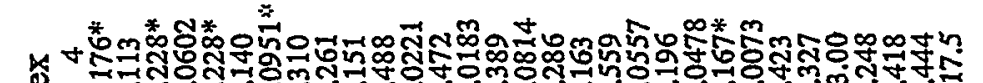

ฬั

悬

四

蒠

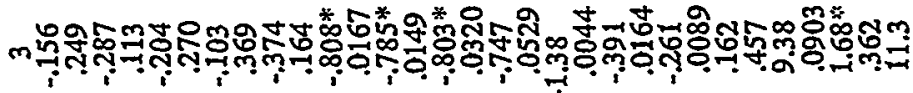

욜

马

ب

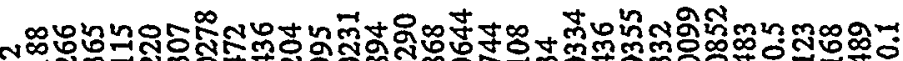

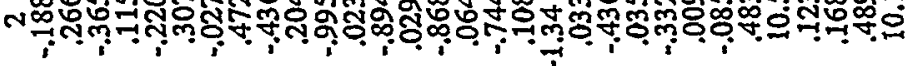

웅

-ำก을

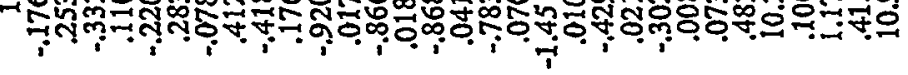

怘

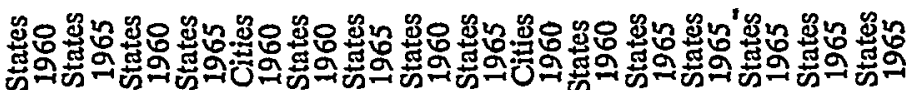

ช

㳕

密

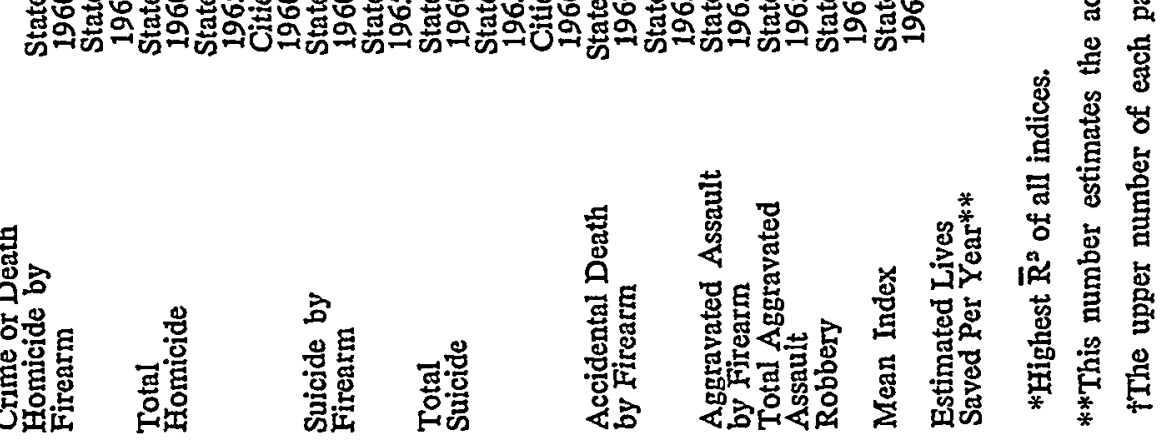


The next to last line of Table A-2 gives the mean value of the index for states in 1965. Some variation among estimated coefficients is due to changes in this average value.

The probabilities of sign error indicate that some of our conclusions, viz., gun control cuts down suicide and accidental death by firearm rates and has little influence on robbery and aggravated assault by firearm, would have been reached regardless of the index chosen. Homicides and total aggravated assaults are a different matter. For these crimes, the choice of index can make a considerable difference in the estimated effect of gun control. In total homicidesstates-1960, for example, all the estimated coefficients are negative but the probability that the true coefficient is negative ranges from .14 (index 4) to .42 (index 6).

We attempted to use variations among indices to make inferences about the relative effectiveness of different types of laws. Indexes 4 and 5, for example, which weight dealer licensing and record keeping relatively heavily, generally perform well for homicide. On the other hand, index 3 , which weights license to purchase very heavily, seems to do well with respect to suicides.

Unfortunately, when we employed more refined techniques in an attempt to isolate the effect of each type of law, we could obtain no significant or even meaningful results.* This failure may have been due to multicollinearity among individual law categories (a statistical difficulty) or to some circumstance such as interactions of laws which make combinations more effective than the sum of effects of individual laws.

Finally, we should mention that standard tests of the regression model were made. We checked the assumption of normal disturbance terms with chi-square tests and normal probability plots of the residuals. Linearity assumptions were checked with residual plots. The regression assumptions were well approximated in all cases.

\footnotetext{
* We tried entering eaeh legislative category as a "dummy variable" and we also split the categories into blocks and attempted to measure the effect of each block independently.
} 